\title{
Controlling incisor torque with completely customized lingual appliances
}

\author{
Ons Alouini' ${ }^{1}$ Michael Knösel ${ }^{2,3,4} \cdot$ Moritz Blanck-Lubarsch $^{5} \cdot$ Hans-Joachim Helms $^{6} \cdot$ Dirk Wiechmann $^{7,8}$
}

Received: 21 April 2019 / Accepted: 11 March 2020 / Published online: 29 May 2020

(c) The Author(s) 2020

\begin{abstract}
Purpose To test the null hypothesis of no significant deviation between the center of rotation $\left(\mathrm{C}_{\mathrm{ROT}}\right)$ and the center of resistance $\left(\mathrm{C}_{\mathrm{RES}}\right)$ during space closure in Angle class II division 2 subjects achieved using a completely customized lingual appliance (CCLA) in combination with class II elastics and elastic chains.

Methods This retrospective study included 29 patients (male/female 11/18; mean age 15.6 [13-27] years) with inclusion criteria of an Angle class II/2 occlusion of least of half of a cusp, maxillary dental arch spacing, completed CCLA treatment (WIN, DW Lingual Systems, Bad Essen, Germany) in one center with a standardized archwire sequence and use of class II elastics and elastic chains only. Maxillary incisor root inclination was assessed by X-ray superimpositions of the maxilla

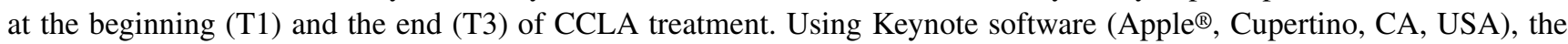
incisor's $C_{R O T}$ was assessed with the point of intersection of the incisor axes (T1; T3) following vertical correction of overbite changes. $\mathrm{C}_{\mathrm{RES}}$ was defined at $36 \%$ of the incisor's apex-incisal edge distance.

Results The null hypothesis was rejected: the mean $\mathrm{C}_{\mathrm{ROT}}-\mathrm{C}_{\mathrm{RES}}$ difference was $52.6 \%(p<0.001)$. The mean $\mathrm{C}_{\mathrm{ROT}}$ was located at $88.6 \%$ (min-max $51-100 \%$ ) of the incisor's apex-incisal edge distance. Although $6.9 \%$ of $\mathrm{C}_{\mathrm{ROT}}$ were located between the $\mathrm{C}_{\mathrm{RES}}$ and the alveolar crest, the vast majority (93.1\%) were assessed between the alveolar crest and the incisal edge, or beyond.

Conclusion CCLAs can create upper incisor palatal root torque even in cases in which lingually oriented forces applied incisally to the center of resistance of the upper incisors counteract these intended root movements.
\end{abstract}

Keywords Malocclusion Angle class II, division $2 \cdot$ Tooth inclination $\cdot$ Incisor third-order angles $\cdot$ Lingual orthodontic appliances · Overbite

\section{Kontrolle des Schneidezahntorques mit vollständig individuellen lingualen Apparaturen}

\section{Zusammenfassung}

Ziel Es wird die Nullhypothese getestet, dass bei der Korrektur der lückigen Angle-Klasse II/2-Malokklusion mit einer vollständig individuellen lingualen Apparatur (,,completely customized lingual appliance“, CCLA) keine signifikante Abweichung zwischen dem Rotationszentrum $\left(\mathrm{C}_{\mathrm{ROT}}\right)$ und dem Widerstandszentrum $\left(\mathrm{C}_{\mathrm{RES}}\right)$ der Oberkieferinzisivi während der Bisslagekorrektur und des Lückenschlusses mit Klasse-II-Gummizügen und elastischen Ketten auftritt.

Dr. Ons Alouini

ons.alouini@hotmail.fr

1 Private Practice, Montpellier, France

2 Department of Orthodontics, University Medical Center (UMG), Göttingen, Germany

3 Department of Paediatric Dentistry and Orthodontics, Faculty of Dentistry, Universidad de La Frontera (UFRO), Temuco, Chile
4 Private Practice, Hamburg, Germany

5 Department of Orthodontics, University of Münster, Münster, Germany

6 Department of Medical Statistics, University Medical Center (UMG), Göttingen, Germany

7 Department of Orthodontics, Hannover Medical School (MHH), Hannover, Germany

8 Private Practice, Bad Essen, Germany 
Methoden Es wurden 29 Patienten $(\mathrm{m}: \mathrm{w}=11: 18$, mittleres Alter 15,6 [13-27] Jahre) in diese retrospektive Studie gemäß folgender Inklusionskriterien aufgenommen: Angle-Klasse II/2-Okklusion von mindestens einer halben Prämolarenbreite, lückiger oberer Zahnbogen, abgeschlossene CCLA-Behandlung (WIN, DW Lingual Systems, Bad Essen) an einem Standort mit standardisierter Bogensequenz sowie ausschließlicher Verwendung von Klasse-II-Gummizügen und elastischen Ketten zum Lückenschluss. Die Wurzelinklination der oberen Inzisivi wurde per Röntgenüberlagerungen der Maxilla zu Beginn (T1) und am Ende (T3) der CCLA-Behandlung bestimmt. Unter Verwendung der Software Keynote (Apple ${ }^{\circledR}$, Cupertino/CA, USA) wurde das C $_{\text {ROT }}$ der Inzisivi durch den Schnittpunkt der Schneidezahnachsen (T1; T3) nach vertikaler Korrektur therapeutischer Overbite-Veränderungen bestimmt. Das $\mathrm{C}_{\mathrm{RES}}$ wurde per definitionem auf $36 \%$ der Apex-Schneidekante-Distanz festgelegt.

Ergebnisse Die Nullhypothese wurde zurückgewiesen: Die mittlere Differenz zwischen $\mathrm{C}_{\mathrm{ROT}}$ und $\mathrm{C}_{\mathrm{RES}}$ betrug mehr als eine halbe Zahnlänge (52,6\%). Das mittlere $\mathrm{C}_{\mathrm{ROT}}$ lag im Bereich der Zahnkrone bei 88,6\% (min-max 51-100\%) der Distanz von Apex zu Schneidekante. Zwar lagen 6,9\% der $C_{\text {ROT }}$ zwischen dem $C_{\text {RES }}$ und dem Alveolarkamm, doch die deutliche Mehrheit $(93,1 \%)$ befand sich im Bereich der Zahnkrone oder jenseits davon.

Schlussfolgerung Mit CCLA ist auch bei schwierigen Ausgangssituationen die kontrollierte Retraktion der Oberkieferfrontzähne mit adäquatem palatinalen Schneidezahn-Wurzeltorque möglich.

Schlüsselwörter Malokklusion Angle-Klasse II/2 $\cdot$ Zahnneigung $\cdot$ Inzisivenwinkel 3. Ordnung $\cdot$ Linguale kieferorthopädische Apparaturen · Overbite

\section{Introduction}

Occurrence of Angle class II division 2 (II/2) malocclusion varies between different populations [1]: While recent French, Swedish, and Turkish studies have reported lower prevalence rates, ranging from 1.8 to $5.4 \%$ [2-4], British and Croatian researchers have reported an incidence of $10 \%$ (British) or even $18 \%$ (Croatian population) [5, 6]. Orthodontic corrections are considered to be more difficult in those cases compared with Angle class II division 1 malocclusions, as incisor torque corrections are distinctively more difficult to implement, due to the increased and permanent labial resting pressure forces caused by the lips [7-9]. Achieving orthodontic treatment goals in those Angle class II/2 malocclusion subjects is even more challenging in combination with generalized dental arch spacing. Space closure in subjects with distal occlusion in combination with posteriorly inclined upper incisors requires forces that are diametrically opposed to the forces and moments needed to achieve adequate incisor axial and root inclination. While the use of elastic chains and class II elastics is common for simultaneous space closure and occlusal adjustments, it complicates incisor torque control in Angle class II/2 subjects by producing forces that reduce incisor root inclination without providing additional counteracting moments. Therefore, the orthodontic challenge in these subjects is aggravated by an enhancement of the retroinclination of maxillary incisors, along with a worsening of deep bite commonly associated with Angle class II/2 malocclusion. A variety of approaches have been developed to overcome this dilemma. The segmented arch technique as described by Burstone [10] represents a sophisticated approach for simultaneous space closure by retraction and uprighting of incisors, by generating a distalizing force vector apically to the center of resistance leading to posterior movement of the incisors combined with a proclining inclination change. Also, closing-loop mechanics with nonsegmented labial archwires may be suitable for incisor retraction along with an adequate proclination, making use of appropriate gable bends mesially and distally of the retraction loops. However, despite these sophisticated approaches, the most common clinical approaches include space closure by either elastic chains or class I sliding mechanics, both of which are capable of achieving space closure, but have the immanent challenge of producing force vectors counteracting third-order incisor correction by palatal root torque required in Angle class II/2 treatments.

Consequently, the challenge in correcting this type of malocclusion using elastic power chains and class II elastics consists of creating an adequate moment that not only equalizes the detrimental forces, but also exceeds them in magnitude, in order to apply an adequate palatal torque to the incisors during space closure and class II bite correction. Using fixed orthodontic appliances, this counteracting moment (couple of forces) is commonly attempted with a rectangular archwire in the rectangular bracket slot. Based on a finite element analysis, Liang et al. [11] suggested that conventional lingual appliances are more prone to a loss of torque control of the maxillary incisors during retraction than labial appliances. They concluded that, compared with labial techniques, lingual appliances should be designed to increase lingual root torque [11]. 


\section{Study objective}

The aim of this study was to evaluate the effectiveness of a completely customized lingual appliance (CCLA; slot dimensions: $0.018 \times 0.025$ inches ribbonwise; WIN, DW LingualSystems, Bad Essen, Germany) in creating a tooth movement, specifically upper incisor palatal root torque, in cases with generalized spacing and an Angle class II/2 malocclusion, using common space closure mechanics, such as power chains and intermaxillary elastics. We tested the null hypothesis of no significant deviation between the center of rotation $\left(\mathrm{C}_{\mathrm{ROT}}\right)$ and the center of resistance $\left(\mathrm{C}_{\mathrm{RES}}\right)$ following space closure in Angle class II/2 subjects achieved using a CCLA in combination with class II elastics and elastic chains.

\section{Subjects}

\section{Inclusion and exclusion criteria}

All consecutive patients treated with a CCLA (WIN; DW Lingual Systems; Bad Essen, Germany) and debonded in the time period from 1 March 2013 to 30 June 2016 in one orthodontic center (Prof. Dr. Wiechmann, Dr. Beyling and colleagues, Bad Essen, Germany) were screened for potential eligibility and were consecutively selected if they met the following inclusion criteria:

- Full permanent dentition, including eruption of second molars

- An Angle class II molar and canine occlusion of at least half of a cusp on at least one side at the beginning of Angle class II correction (T2)

- Upper incisor inclination U1/PP $<115^{\circ}$

- Spacing in the upper dental arch

- Treatment completed with a completely customized lingual appliance (CCLA) in combination with class II elastics and elastic power chains

Subjects were excluded if they fulfilled one of the following exclusion criteria:

- Use of additional skeletal anchorage or fixed functional appliances for sagittal bite correction, such as Herbst appliances

- Dental aplasia

- Periodontal diseases or alveolar bone loss as evident in panoramic radiographs

- Treatment plan with extractions

\section{Included subjects}

After application of the inclusion and exclusion criteria, a total of 29 Angle class II division 2 malocclusion subjects (male/female ratio 11/18; mean age at the beginning of treatment (T1): 15.6 [range 13-27] years) were included. None of the patients received skeletal anchorage or fixed functional appliances. No patient was excluded from this retrospective analysis for any other reasons such as missed appointments, lack of compliance, or missing records or informed consent to anonymized data release forms, which is occasionally seen in sample compositions of retrospective studies [12].

\section{Methods}

\section{Lingual archwire sequence}

All subjects were treated with a CCLA (WIN, DW LingualSystems, Bad Essen; Germany) and a standardized sequence of archwires: an initial NiTi with round diameter (diameter depending on extent of crowding $0.012^{\prime \prime}, 0.014^{\prime \prime}$, or $0.016^{\prime \prime}$ ), followed by a rectangular $0.016^{\prime \prime} \times 0.022^{\prime \prime} \mathrm{NiTi}$ archwire, and a $0.016^{\prime \prime} \times 0.024^{\prime \prime}$ stainless steel wire with an incorporated maxillary canine to canine extra-torque bend of $13^{\circ}$. One patient received an additional $0.016^{\prime \prime} \times 0.024^{\prime \prime}$ stainless steel wire with an extra-torque of $21^{\circ}$. A TMA $0.018^{\prime \prime} \times 0.018^{\prime \prime}$ archwire was used for finishing in all treatments. Space closure and Angle class II correction was achieved with power chains (Morita Energy Chain, Rocky Mountain Orthodontics, Denver, CO, USA) and class II elastics following incorporation of the stainless steel archwires in both arches.

\section{Assessment of occlusion and spacing}

Sagittal occlusion was measured using high-resolution, digital, intra-oral photographs (D200, with Nikkor $105 \mathrm{~mm}$; Nikon, Tokyo, Japan) at bonding (T1), following leveling and aligning and prior to using class II elastics (T2), and after debonding (T3). The photographs were taken directly, without an intra-oral mirror, using cheek retractors (Fig. 1). The camera axis was as close as possible to $90^{\circ}$ to the premolar/posterior tooth group. We used the premolars to assess the extent of sagittal occlusion. For the assessment of the sagittal occlusion, we compared the position of the upper first premolar to that of the two lower premolars. We defined the Angle class I in our study by the upper premolar being perfectly centered with the lower premolars, equivalent to a value of $0 \mathrm{~mm}$. If the cusp of the upper first premolar is centered with the mesial side of the first lower premolar, it was defined as a full Angle class II occlu- 


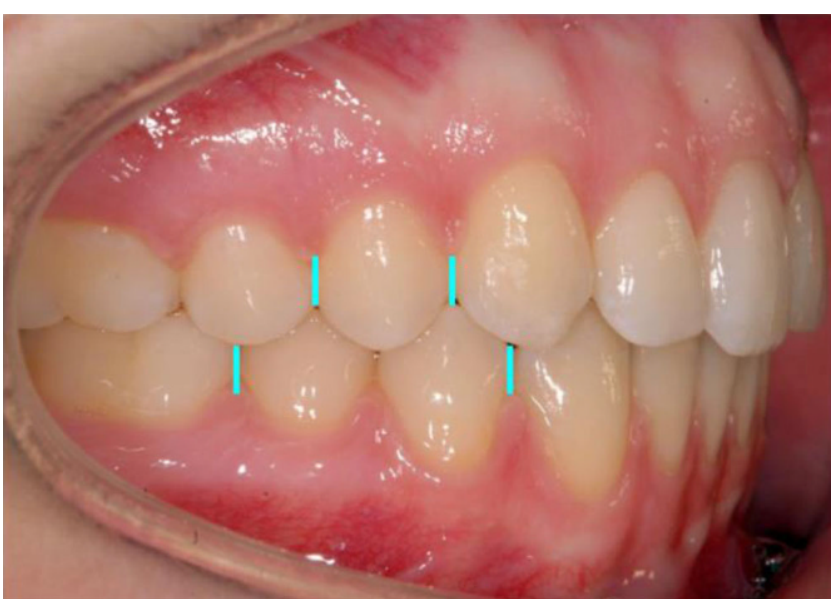

Fig. 1 Digital, high-resolution intra-oral photographs were used to assess sagittal occlusion, with the camera axis as close as possible to $90^{\circ}$ to the premolar/posterior tooth group. Premolars were used to assess the extent of the sagittal occlusion. See text for details

Abb. 1 Digitale hochauflösende intraorale Fotos wurden zur Bestimmung der sagittalen Okklusion verwendet, wobei die Kameraachse so nah wie möglich an der Senkrechten zur Prämolar-/Seitenzahngruppe ausgerichtet wurde. Das Ausmaß der sagittalen Okklusion wurde anhand von Prämolaren beurteilt. Details s. Text

sion. An edge-to-edge position of the respective mesial and distal sides of upper and lower first premolar was defined as a sagittal distal occlusion of $1 / 2$ cusp. The true dimensions of the assessed premolar and malocclusion on the digital photographs were assessed using a calibration technique previously employed [13]: The intraoral photographs were scaled to the corresponding plaster casts by adjusting the dimensions of the upper first premolar to its corresponding dimensions taken from direct cast measurements, using a sliding caliper. In cases in which there were different extents of sagittal occlusion on either side, the side with greater Angle class II occlusion was chosen for assessment. A neutral occlusion was defined by the first maxillary premolar centered between the lower premolars and was assigned a value of $0 \mathrm{~mm}$ of sagittal malocclusion. Deviations from neutral sagittal canine occlusion in the posterior direction (i.e., distal or Angle class II occlusion) were assigned positive $\mathrm{mm}$ values. Overbite measurements were performed on corresponding plaster cast models at $\mathrm{T} 1$ and at the end of treatment (T3). Wax bites taken in centric relation were utilized to correctly position upper and lower plaster casts, and the maximum overlapping was marked on the lower incisors with a pencil tip of $0.35 \mathrm{~mm}$ thickness. Distances between the pencil mark and the incisal edge of the incisor were taken using a sliding caliper (Dentaurum, Münchner Modell, Ispringen, Germany). Likewise, maxillary spacing was measured on the plaster casts taken at $\mathrm{T} 1$ and T3. All assessments of sagittal occlusion, incisor inclination, and overbite were performed manually by one operator (OA), twice, and the mean values for each of the repeated measurements were used for analysis.

\section{Incisor inclination assessments}

\section{Definition of the center of resistance}

In order to account for potential individual deviations between the root axis and the crown axis of maxillary central incisors which seen especially in Angle class II/2 subjects $[14,15]$, one of three digital incisor templates (with different curvatures of the cingulum) provided by Cephalometrics ${ }^{\circledR}$ software (Cephalometrics, Carpentras, France) were superimposed on and sized to these incisors using the positions of the apex and the tip (Figs. 2 and 3). The total length of every incisor measured, from apex to incisal edge, was graded in percent by a virtual ruler using Keynote software (Apple ${ }^{\circledR}$, Cupertino, CA, USA). The template length was assigned the value of $100 \%$.

Following the calculations of Burstone and Pryputniewicz who described the location of the center of resistance $\left(\mathrm{C}_{\mathrm{RES}}\right)$ at a point one-third of the distance from the alveolar crest to the apex [16], the $\mathrm{C}_{\mathrm{RES}}$ of the tooth was defined to be located at $36 \%$ of the total length of the tooth, starting from the apex and taking account of the distance
Fig. 2 One out of three incisor templates was individually chosen in order to account for deviating crown-root angles in Angle class II/2 subjects [14, 15] Abb. 2 Von 3 Schneidezahn-Templates wurde jeweils eins individuell ausgewählt, um der Variation der Kronen-Wurzel-Winkel bei Angle-Klasse II/2-Patienten Rechnung zu tragen $[14,15]$

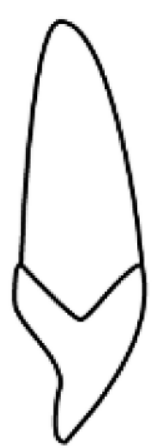

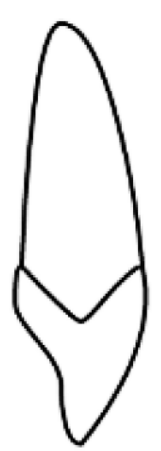

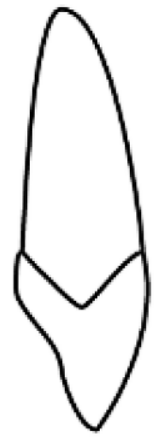



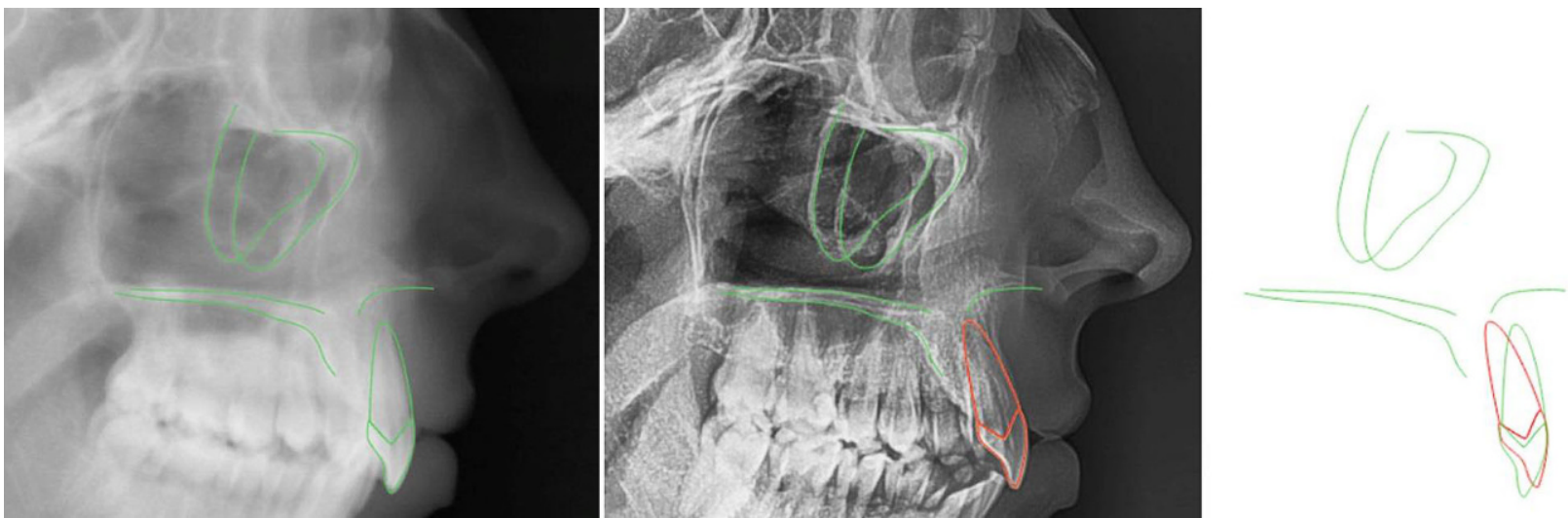

Fig. 3 Using Cephalometrics ${ }^{\circledR}$ software, lateral X-ray superimpositions were performed on the maxilla using the stable structures of the maxilla (i.e., the anterior part of the zygomatic processus), as suggested by Björk and Skieller [17]. Movements of the incisors were assessed with reference to the maxillary bone, as maxillary structures may be subject to alterations in position during treatment

Abb. 3 Mit Hilfe der Cephalometrics ${ }^{\circledR}$-Software wurden laterale Fernröntgen-Überlagerungen der Maxilla angefertigt, die nach der Empfehlung von Björk und Skieller [17] die stabilen Strukturen der Maxilla (d.h. der anteriore Anteil des Processus zygomaticus) als Referenz nutzten. Schneidezahnbewegungen wurden mit Bezug auf die maxillären Hartgewebe ermittelt, da diese Strukturen während der Behandlung Positionsveränderungen erfahren können

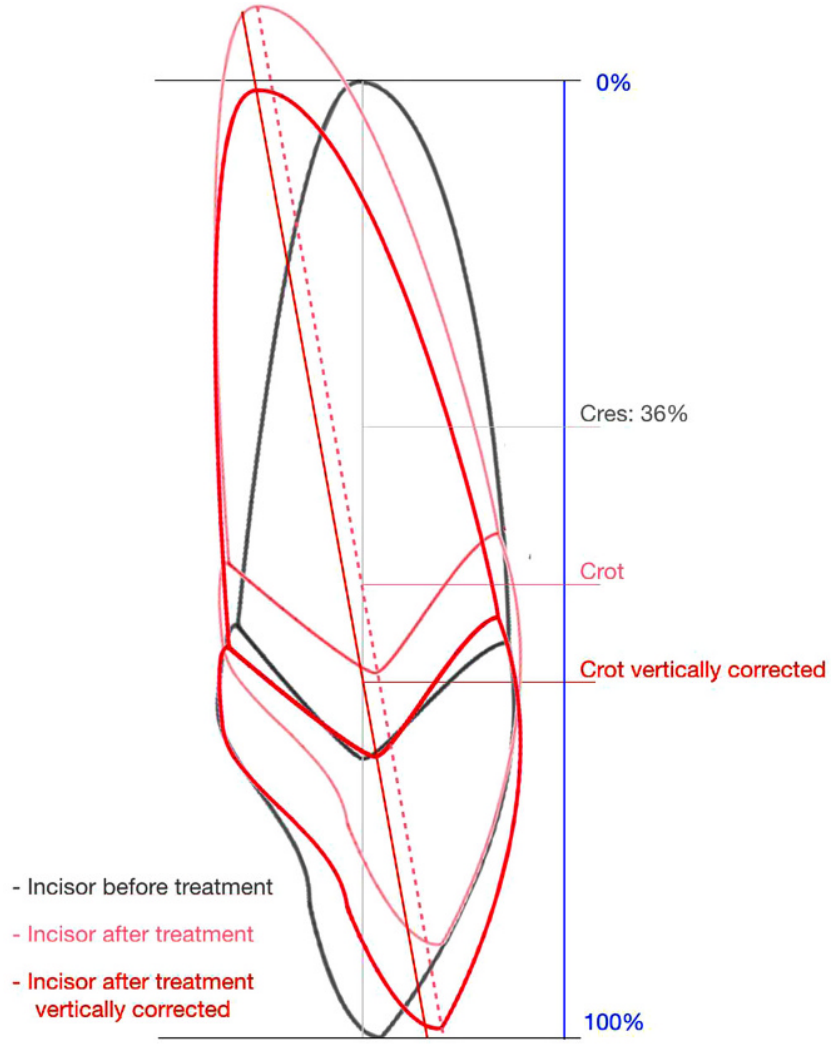

Fig. 4 Definition of incisor landmarks

Abb. 4 Definition der Inzisiven-Referenzpunkte between the enamel-cement junction and the periodontally attached root (Fig. 4).

\section{Primary endpoint: definition of the center of rotation}

To assess the center of rotation $\left(\mathrm{C}_{\mathrm{ROT}}\right)$ of the incisor movement during treatment, digital pre- (T1) and posttreatment radiographs (T3) were superimposed using the stable structures of the maxilla (i.e., the anterior part of the zygomatic processus), as suggested by Björk and Skieller [17]. The $\mathrm{C}_{\mathrm{ROT}}$ was assessed by the intersection of the tooth axes of the maxillary incisor before and after treatment. Using the virtual ruler, the location of the $\mathrm{C}_{\mathrm{ROT}}$ was documented as a percentage of the total incisor length, starting with $0 \%$ at the apex [18]. In order to compensate for vertical proportions of incisor position changes during treatment, the posttreatment template was shifted along the incisor axis by the same amount in the opposite direction of the movement, in order to delete the vertical effect (Fig. 4). These vertically corrected $\mathrm{C}_{\mathrm{ROT}}$ were separately documented and were defined as the primary endpoint of this study. For the statistical analysis, the maximum distance was set to $100 \%$. $\mathrm{A} \mathrm{C}_{\mathrm{ROT}}$ located beyond the incisor's edge (i.e., the transition from root torque to parallel shift) was also assigned a value of $100 \%$. These movements always include torque control, yielding a combination of a distally oriented crown movement with an adequate counterclockwise moment produced by the bracket slot/archwire interplay.

\section{Method error analysis}

For assessing the potential method error for assessment of the $\mathrm{C}_{\mathrm{ROT}}$, measurements of 10 randomly selected patients 
were repeated (M1; M2) by the same examiner (OA). The mean difference of (M1-M2) was $0.42 \%$ and no significant difference was detected (standard deviation [SD] 2.5; $p=0.54$ by sign test). A small variation between a minimum of $-2 \%$ and a maximum of $7 \%$ was considered acceptable compared to the differences seen between $\mathrm{C}_{\mathrm{RES}}$ and $\mathrm{C}_{\mathrm{ROT}}$.

\section{Statistical analysis}

To assess the quality of incisor movements during CCLA treatment, the measurement data for upper incisor inclination to the palatal plane (U1/PP), sagittal occlusion, overbite, the extent of spacing of the maxillary dental arch and the location of the $\mathrm{C}_{\mathrm{ROT}}$ were analyzed descriptively using mean and standard deviation (SD), as well as minimum and maximum values (min-max) at specific time points. The primary endpoint was the location of the $\mathrm{C}_{\mathrm{ROT}}$ in relation to $\mathrm{C}_{\mathrm{RES}}$

The potential difference between the center of rotation $\left(\mathrm{C}_{\mathrm{ROT}}\right)$ and the center of resistance (referred to the fixed value $\mathrm{C}_{\mathrm{RES}}=0.36$ ) was analyzed using a nonparametric sign test, due to the asymmetric data distribution. The sign test was also used to assess the method error between repeated measurements of M1 and M2. The change in sagittal occlusion, U1/PP and overbite between T1 and T3 was analyzed using a paired t-test. The significance level was set to $\alpha=5 \%$. All statistical analyses were derived using the statistical software SAS version 9.4 (SAS, Cary, NC, USA).

\section{Retrospective power calculation}

With the available sample size of 29 patients and different assumed standard deviations of 20 and 30, a significance level of $\alpha=5 \%$, power of $90 \%$, as well as $C_{\text {RES }}=36 \%$, the following true expected effect sizes $(\Delta=$ expected value of $\mathrm{C}_{\mathrm{ROT}}-\mathrm{C}_{\mathrm{RES}}$ ) were established: $\Delta=12.5 \%$ (assuming $S D=$ 20 ) and $\Delta=18.7 \%$ (assuming $S D=30$ ).

\section{Results}

The individual occlusal features, incisor position changes, and location of $\mathrm{C}_{\mathrm{ROT}}$ are provided in Table 2 .

The mean $\mathrm{C}_{\mathrm{ROT}}$ was at $88.6 \%$ (min-max, $51-100 \%$ ) of the incisor's apex-incisal edge distance and this difference (mean $\mathrm{C}_{\mathrm{ROT}}-\mathrm{C}_{\mathrm{RES}}, 52.6 \%$ ) was found to be statistically significant $(p<0.001)$. While $6.9 \%$ of $\mathrm{C}_{\mathrm{ROT}}$ were located between the $\mathrm{C}_{\mathrm{RES}}$ and the alveolar crest, the vast majority $(93.1 \%)$ were assessed between the alveolar crest and the incisal edge or beyond. The distribution of the individual locations of the $\mathrm{C}_{\mathrm{ROT}}$ is illustrated in Fig. 5. Table 2 also lists the result of the one sample t-test of the null hypothesis.
Table 2 Descriptive statistical summary of occlusal features, incisor position changes, and location of center of rotation $\left(\mathrm{C}_{\mathrm{ROT}}\right)$ with and without vertical correction by overbite changes, in $\%$ of the complete incisor $(0=$ apex and $100=$ incisor tip $)$

Tab. 2 Zusammenfassung der deskriptiven Statistik okklusaler Charakteristika, Positionsänderungen der Schneidezähne und Position des Rotationszentrums $\left(\mathrm{C}_{\mathrm{ROT}}\right)$ mit und ohne vertikale Korrektur durch Overbite-Veränderungen, in Prozent der gesamten Schneidezahnlänge $(0 \%=$ Apex, $100 \%=$ Schneidekante $)$

\begin{tabular}{|c|c|c|}
\hline \multirow{3}{*}{$\begin{array}{l}\text { Sagittal occlusion } \\
(\text { Angle class } \mathrm{II}), \mathrm{mm} \\
\text { mean } \pm \mathrm{SD}[\mathrm{min}, \max ]\end{array}$} & $\mathrm{T} 2$ & $4.55 \pm 1.17[3.5,7]$ \\
\hline & $\mathrm{T} 3$ & $0.17 \pm 0.33[0,1.5]$ \\
\hline & $\Delta \mathrm{T} 2-\mathrm{T} 3$ & $\begin{array}{l}4.4 \pm 1.23[3,7] \\
p<0.001^{\mathrm{b}}\end{array}$ \\
\hline \multirow{3}{*}{$\begin{array}{l}U 1 / P P,{ }^{\circ} \\
\text { mean } \pm \mathrm{SD}[\min , \max ]\end{array}$} & $\mathrm{T} 1$ & $103.14 \pm 6.07[88.2,114.8]$ \\
\hline & $\mathrm{T} 3$ & $110.89 \pm 5.74[99.5,121.1]$ \\
\hline & $\Delta \mathrm{T} 1-\mathrm{T} 3$ & $\begin{array}{l}7.74 \pm 5.89[0,22.3] \\
p<0.001^{\mathrm{b}}\end{array}$ \\
\hline $\begin{array}{l}\text { Maxillary arch spacing, } \\
m m \\
\text { mean } \pm \mathrm{SD}[\mathrm{min}, \max ]\end{array}$ & $\mathrm{T} 1$ & $2.97 \pm 1.89[1,10]$ \\
\hline \multirow{3}{*}{$\begin{array}{l}\text { Overbite, } \mathrm{mm} \\
\text { mean } \pm \mathrm{SD}[\min , \max ]\end{array}$} & $\mathrm{T} 1$ & $4.38 \pm 1.01[2.5,7]$ \\
\hline & $\mathrm{T} 3$ & $1.52 \pm 0.43[0.5,2]$ \\
\hline & $\Delta \mathrm{T} 1-\mathrm{T} 3$ & $\begin{array}{l}2.88 \pm 1[0,5.5] \\
p<0.001^{\mathrm{b}}\end{array}$ \\
\hline $\begin{array}{l}C_{R O T}, \% \\
\text { mean } \pm \mathrm{SD}[\min , \max ]\end{array}$ & & $\begin{array}{l}88.65 \pm 17.4[47,100] \\
p<0.0001\end{array}$ \\
\hline $\begin{array}{l}\text { Primary endpoint: } \\
C_{R O T}(\text { vertically corrected }), \\
\text { mean } \pm \mathrm{SD}[\mathrm{min}, \max ]\end{array}$ & & $\begin{array}{l}88.62 \pm 16.47[51,100] \\
p<0.001^{\mathrm{a}}\end{array}$ \\
\hline
\end{tabular}

$S D$ standard deviation, $\min$ minimum, $\max$ maximum

aSign test

${ }^{b}$ Paired t-test

\section{Maxillary space closure}

At $\mathrm{T} 1$, the mean total maxillary spacing was $3.0 \mathrm{~mm}$ (SD 1.9; min-max $1-10 \mathrm{~mm}$ ). At the end of CCLA treatment (T3), all maxillary spacings were closed, as planned in the target set-up (Tables 1 and 2).

\section{Angle class II correction}

Mean sagittal malocclusion as measured on the worse side at T2 (following leveling and aligning) was $4.6 \mathrm{~mm}$ distal occlusion (SD 1.2; $\min -\max 3.5-7 \mathrm{~mm}$ ) which had improved in all patients to a mean $0.2 \mathrm{~mm}$ (SD 0.3; min-max $0-1.5 \mathrm{~mm}$ ) at T3. At T3, 21 out of 29 subjects had a perfect Angle class I occlusion $(0 \mathrm{~mm})$, whereas 7 patients $(24.1 \%)$ showed a minor distal occlusion of $0.5 \mathrm{~mm}$ and one subject $(3.4 \%)$ had a distal occlusion of $1.5 \mathrm{~mm}$. The mean sagittal correction measured on the worse side was $4.4 \mathrm{~mm}$ (SD 1.2; min-max 3-7 mm; Tables 1 and 2). 


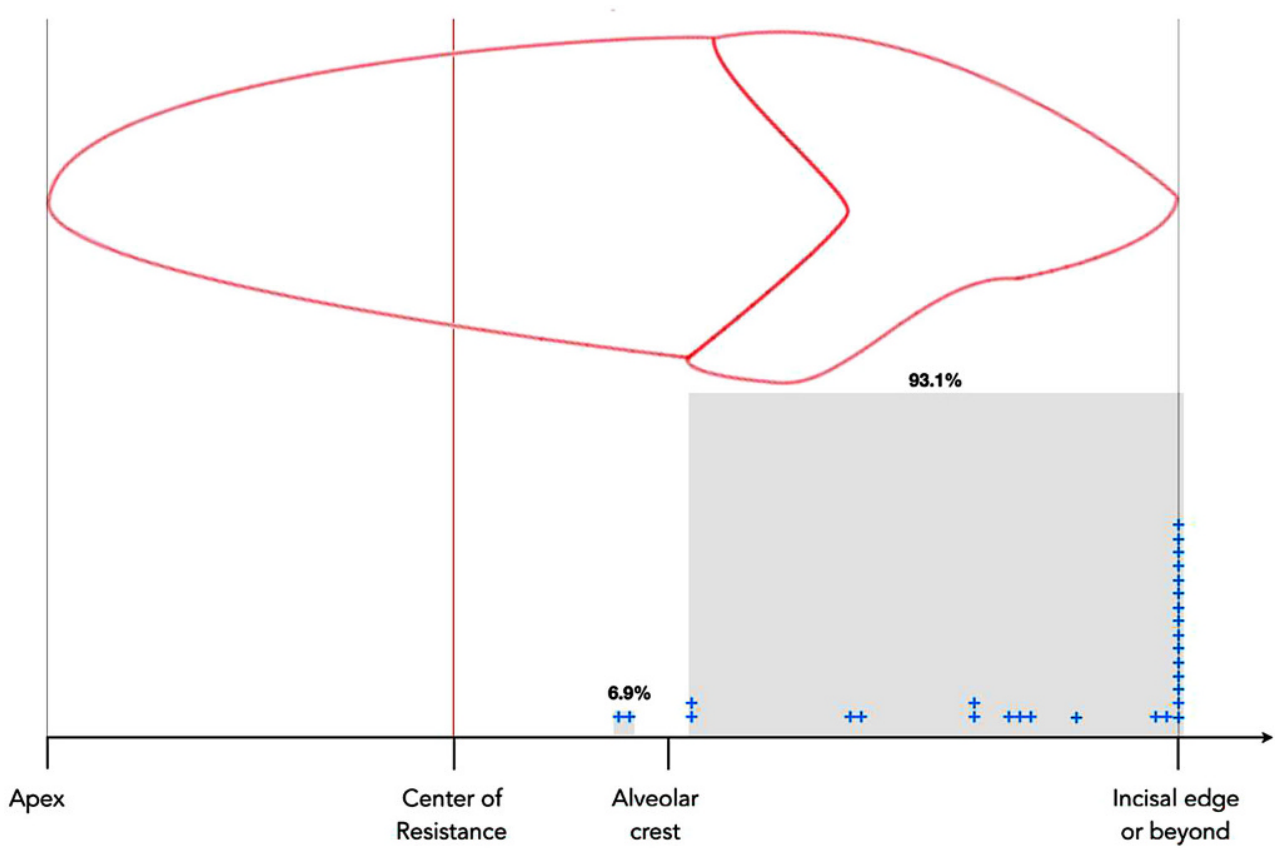

Fig. 5 Distribution of the individual locations of the center of rotation $\left(\mathrm{C}_{\mathrm{ROT}}\right)$ as $\%$ of the complete incisor $(0=$ apex and $100=$ incisor edge $)$. No $\mathrm{C}_{\text {ROTs }}$ were found below or at the center of resistance ( $\left.\mathrm{C}_{\mathrm{RES}}\right): 0 \geq \mathrm{x} \leq 36$. In 2 cases $(6.9 \%)$, the $\mathrm{C}_{\mathrm{ROT}}$ was located between the $\mathrm{C}_{\mathrm{RES}}$ and the alveolar crest $(36>x \leq 55)$, while the $\mathrm{C}_{\mathrm{ROT}}$ was located in $93.1 \%$ (27 patients) between the alveolar crest and the incisal edge, or beyond (55>x $\left.\leq 100\right)$

Abb. 5 Verteilung der individuellen Positionen des Rotationszentrums $\left(\mathrm{C}_{\mathrm{ROT}}\right)$ in \% der Gesamtlänge des Inzisivus, $(0 \%=\mathrm{Apex}$, $100 \%=\mathrm{Schneide-}$ kante). Kein $\mathrm{C}_{\mathrm{ROT}}$ wurde am oder apikal des Widerstandszentrums gefunden $(0 \geq \mathrm{x} \leq 36)$. In zwei Fällen $(6,9 \%)$ lag das $\mathrm{C}_{\mathrm{ROT}} \mathrm{zwischen} \mathrm{C}_{\mathrm{RES}}$ und dem Alveolarknochenkamm (36>x $\leq 55)$, während es in 93,1\% (27 Patienten) der untersuchten Fälle zwischen dem Alveolarknochenkamm und der Inzisalkante oder darüber hinaus festgestellt wurde $(55>\mathrm{x} \leq 100)$

\section{Overbite correction}

All of the 29 patients had a deep bite ( $>2 \mathrm{~mm}$ ) at T1. Deep bite correction was achieved in all patients: at T1, the mean overbite was $4.4 \mathrm{~mm}$ (SD $1.0 \mathrm{~mm}$ ), which decreased significantly $(p<0.001)$ by a mean difference of $2.9 \mathrm{~mm}$ (SD $1.0 \mathrm{~mm}$ ) to a mean $1.5 \mathrm{~mm}$ (SD $0.4 \mathrm{~mm}$; Tables 1 and 2).

\section{Treatment duration}

Treatment duration varied from 16-43 months, with a mean value of 28 months (SD 3.5 months) between CCLA bonding and debonding.

\section{Discussion}

\section{Definition of third order tooth movements}

In general, there are three different ways to improve the inclination of a retroclined incisor. If a single force is applied to the crown of the tooth in an anterior direction, the crown is tipped in the buccal direction. Without the simultaneous application of a couple of force with opposite directions (a moment), the tooth will rotate with a center of rotation located inside the root. The location depends on the distance of the applied force to the center of resistance. Some of these types of tooth movements meet the definition of uncontrolled tipping and are typically achieved with a variety of removable appliances or with fixed appliances in combination with round archwires. At the end of such tooth movement, the inclination of the incisor is more positive and, as the crown of the tooth is tipped to the buccal side, space is created, leading to an increased arch length and an improved incisor inclination. However, it is worth noting that this improvement in incisor inclination is not equal to a (root) torque movement or a bodily movement. To achieve a torque movement, the combination of a force and a moment (couple of forces in opposite directions, e.g., a force shifted apically to the $\mathrm{C}_{\mathrm{RES}}$ by a moment created by the segmented arch approach resulting in a palatal root torque) is necessary. Only this combination allows for shifting the center of rotation towards the incisal edge. To achieve movement such as a root torque (torque movement, bodily movement as torque) with a center of rotation close to or at the incisal tip [16], a buccally oriented force on the crown of the tooth has to be combined with a clockwise moment (buccal root torque), or a palatally oriented force on the crown of the tooth has to be combined with a counterclockwise moment (palatal root torque). Typically, buccal root torque is needed in the maxillary anterior segment for dentoalveolar compensation of an Angle 


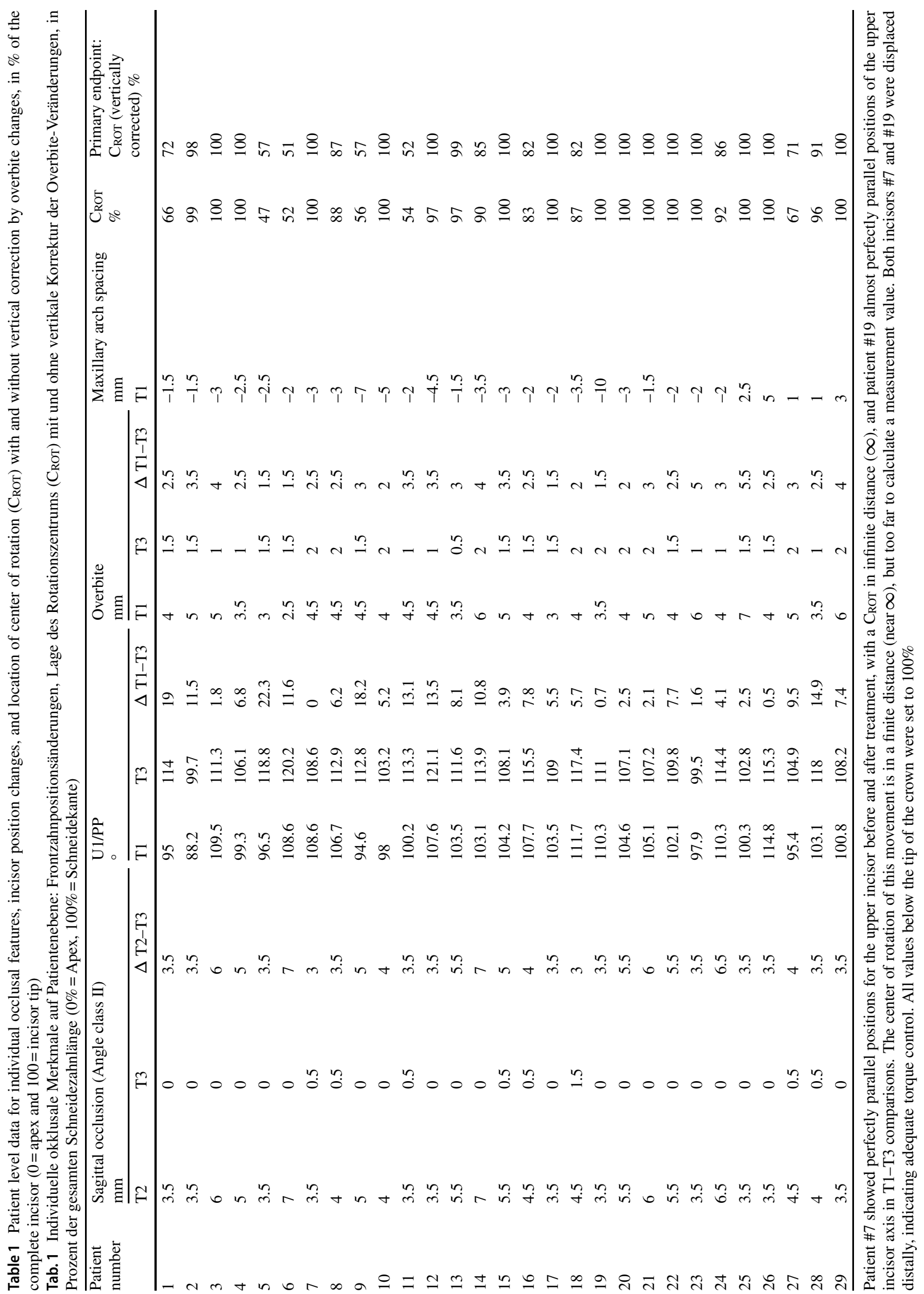


class III malocclusion, whereas palatal root torque in the same segment is needed for most of the nonsurgical Angle class II corrections. If the inclination of a retroclined incisor is corrected by a palatal root torque, no space opening is observed, as the crowns do not move buccally. The third possibility to improve the inclination of a retroclined incisor is controlled tipping of the crown to the buccal side. In this case, the center of rotation is shifted to the apex.

Putting aside these fundamental orthodontic rules, virtually impossible results have been reported by some authors mainly during the past 7 years, regarding the alleged torqueing capabilities of some kinds of clear aligner treatment (CAT) [19-21]. A closer look at the methods applied in these studies has revealed an ambiguous use of the term "torque movements", since they measured the inclination of the labial surface of the incisors on digital dental arches and misinterpreted each inclination change of the labial surface as a bodily movement of torque. The orthodontic community should indeed be aware of the unreflective repetition of this kind of mistake-even in systematic review articles about CAT.

\section{Creating a couple of forces with opposite directions}

The importance of palatal root torque and/or correct incisor inclination for dental arch length and the achievement of a proper molar relationship has been the subject of many studies [22-25]. With fixed appliances, a torque moment is created by the rectangular archwire's action to untwist when engaged in a bracket slot [26], thereby generating a couple of forces with opposite directions or moment that change the inclination of the incisor [25, 27]. Being a free vector, this moment is subject to spatial variability and may be located on any point along the long axis of the tooth, or outside of the tooth. Based on this knowledge, Andrews developed the straight-wire appliance using angulated, preadjusted bracket slots [28]. It is, however, well known that torque expression is highly dependent on archwire dimensions versus slot size [29]. Commonly used conventional labial brackets are manufactured using the technique of metal injection molding. The initially molded bracket-the so-called "brown part"-is about $30 \%$ larger than the final bracket and is made of compressed metal powder. During the sintering process, this oversized bracket is heated up very close to its melting temperature and shrinks in a very uncontrollable way, resulting in high slot tolerances in both directions: positive and negative. In order to avoid situations in which archwires do not fit into undersized bracket slots (negative tolerance), the target slot size is set to a higher value, aggravating the average oversize of the final bracket slot to values of up to $20 \%$ or more [29]. The consequences of increasing torque play by shifting the manufacture of orthodontic brackets from milling or precision casting to metal injection molding (MIM) have been discussed extensively [30-33].

\section{Importance of torque control and lingual treatment}

In lingual orthodontic treatment, third order control is of substantial importance for achieving precision in finishing [34-37]. In a finite element analysis, Liang et al. [11] simulated and compared retraction of incisors with labial and lingual appliances and found that it was critical to control the moment/force ratio and increase lingual root torque properly with lingual appliances. It is noteworthy that, to the best of our knowledge, this topic has been previously addressed on the evidence level of in vitro experiments and retrospective studies, but not with clinical prospective study or randomized, controlled trial designs that addressed outcome differences when comparing labial, lingual or aligner technique approaches to meet a higher level of evidence. In order to address these issues of controlling the moment/ force ratio adequately, the bracket slots of the CCLAs used in this study were made by high-speed milling with manufacturing tolerances of only up to $\pm 2 \mu \mathrm{m}(<0.5 \%)$ [38]. As a consequence, the magnitude of torque expression with these appliances compared to conventional labial or lingual brackets can be easily controlled by the orthodontic specialist [37, 39-45]. In order to account for torque play, the undersized maxillary rectangular $0.016^{\prime \prime} \times 0.024^{\prime \prime}$ stainless steel archwires of the CCLA used here during space closure were provided with an incorporated canine-to-canine extra torque bend of $13^{\circ}$, and, in the case of one patient, $21^{\circ}$. The use of the $0.016^{\prime \prime} \times 0.024^{\prime \prime}$ stainless steel archwires with built-in extra torque bends is crucial for maintaining the necessary moment to counteract and overcome the crown tipping forces in the palatal direction generated using class II elastics and power chains during space closure.

\section{Location of the center of resistance}

According to calculations made by Burstone and Pryputniewicz, the center of resistance $\left(\mathrm{C}_{\mathrm{RES}}\right)$ of an upper incisor is located approximately at a point one-third of the distance from the alveolar crest to the apex [16]. Likewise, Graber et al. [34] reported that the center of resistance in a singlerooted tooth with a parabolic shape should be calculated by multiplying the distance from the alveolar crest to the apex by 0.33 . Proffit et al. [43] took into consideration the condition of the periodontal tissues and described a tooth's center of resistance to be slightly more apical, i.e., "at the approximate midpoint of the embedded portion of the root (i.e., about halfway between the root apex and the crest of the alveolar bone)". Due to the young age of the subjects included in our study and the absence of periodontal diseases or bone loss, the alveolar crest was assigned to be located 
about $2 \mathrm{~mm}$ below the enamel/cement junction [16]. The alveolar crest was approximated by a line, and $2 \mathrm{~mm}$ was subtracted (Fig. 4).

\section{Null hypothesis}

The null hypothesis of no significant deviation between the center of rotation $\left(\mathrm{C}_{\mathrm{ROT}}\right)$ and the center of resistance $\left(\mathrm{C}_{\mathrm{RES}}\right)$ during space closure in Angle class II/2 subjects was rejected. While the center of resistance of the tooth was located at $36 \%$ from the total length of the tooth starting from the apex, the mean $\mathrm{C}_{\mathrm{ROT}}$ was at $88.6 \%$ (min-max, $51-100 \%$ ). This difference (mean $\mathrm{C}_{\mathrm{ROT}}-\mathrm{C}_{\mathrm{RES}}, 52.6 \%$ ) was found to be statistically significant $(p<0.001$, Table 2$)$.

In our study, all $\mathrm{C}_{\mathrm{ROTs}}$ were found to be located above the incisor's $\mathrm{C}_{\mathrm{RES}}$ in the incisal direction, i.e., they were shifted towards the incisal edge or beyond, indicating that neither controlled nor uncontrolled incisor tipping occurred in the treated individuals.

We corrected for vertical (overbite) changes in tooth position during treatment by measuring the vertical position of the incisor before and after treatment and adjusted the center of rotation along the long axis of the tooth with the same distance. One of three incisor templates was individually chosen to account for deviating crown-root angles in Angle class II/2 subjects ([14, 15]; Fig. 2). The same template that was used for the baseline assessment of each incisor was also used for the second assessment of the respective incisor, in order to avoid within-subject changes in incisor shape and dimensions.

\section{Limitations}

The calculation of the incisor's $\mathrm{C}_{\mathrm{RES}}$ as one factor to describe the nature of the achieved tooth movements was based on calculations made by Burstone and Pryputniewicz [16]. As the location of the $\mathrm{C}_{\mathrm{RES}}$ is multifactorially influenced by tooth morphology and the properties and condition of the individual periodontum, slightly different descriptions of the $\mathrm{C}_{\mathrm{RES}}$ have been provided by various authors $[34,46]$, and the extent to which the three-dimensional situation can be generalized has been discussed [47, 48]. However, the definition of the root centroid or $\mathrm{C}_{\mathrm{RES}}$ used here is widely accepted in orthodontic literature and is considered to be a valid orientation to describing incisor movements.

\section{Conclusions}

- Despite the use of elastic chains and class II elastics that are known to worsen incisor torque control in Angle class II/2 subjects, no uncontrolled incisor tipping occurred in the treated individuals.
- While $6.9 \%$ of center of rotation $\left(\mathrm{C}_{\mathrm{ROT}}\right)$ were located between the center of resistance $\left(\mathrm{C}_{\mathrm{RES}}\right)$ and the alveolar crest, the vast majority $(93.1 \%)$ were located between the alveolar crest and the incisal edge or beyond, indicating adequate root torque control by the completely customized lingual appliances (CCLA).

- CCLAs can create upper incisor palatal root torque even in cases in which lingually oriented forces applied incisally to the center of resistance of the anterior upper teeth counteract these intended root movements.

\section{Compliance with ethical guidelines}

Conflict of interest D. Wiechmann is the inventor of the WIN appliance and Managing Director of the manufacturing company DW LingualSystems, Bad Essen, Germany. O. Alouini, M. Knösel, M. BlanckLubarsch and H.-J. Helms declare that they have no competing interests.

Ethical standards This study received full prior approval from the Ethics Committee of the Hannover Medical School (No. 3151-2016). Informed consent to anonymized data release was obtained from all patients or their legal guardians included in this study.

Open Access This article is licensed under a Creative Commons Attribution 4.0 International License, which permits use, sharing, adaptation, distribution and reproduction in any medium or format, as long as you give appropriate credit to the original author(s) and the source, provide a link to the Creative Commons licence, and indicate if changes were made. The images or other third party material in this article are included in the article's Creative Commons licence, unless indicated otherwise in a credit line to the material. If material is not included in the article's Creative Commons licence and your intended use is not permitted by statutory regulation or exceeds the permitted use, you will need to obtain permission directly from the copyright holder. To view a copy of this licence, visit http://creativecommons.org/licenses/by/4. $0 /$.

\section{References}

1. Millett DT, Cunningham SJ, O’Brien KD, Benson PE, de Oliveira CM (2018) Orthodontic treatment for deep bite and retroclined upper front teeth in children. Cochrane Database Syst Rev 2:CD5972

2. Matysiak M, Brochard P, Fouilleul T, Merentier JL, Peyrot B, Rouch M (2003) Dentofacial orthopedics: frequency, geographic distribution and length of treatment for dentomaxillary dysmorphosis. A national study based on data from the general scheme of the national health fund. Rev Méd Assur Mal 34:23-32

3. Bilgic F, Gelgor IE, Celebi AA (2015) Malocclusion prevalence and orthodontic treatment need in central Anatolian adolescents compared to European and other nations' adolescents. Dental Press J Orthod 20:75-81

4. Dimberg L, Lennartsson B, Arnrup K, Bondemark L (2015) Prevalence and change of malocclusions from primary to early permanent dentition: a longitudinal study. Angle Orthod 85:728-734

5. Houston WJB, Stephens CD, Tulley J (1996) A text book of orthodontics. Blackwell, Oxford

6. Legovic M, Mady L (1999) Longitudinal occlusal changes from primary to permanent dentition in children with normal primary occlusion. Angle Orthod 69:264-266 
7. Burstone CJ (1967) Lip posture and its significance in treatment planning. Am J Orthod 53:262-284

8. McIntyre GT, Millett DT (2006) Lip shape and position in class II division 2 malocclusion. Angle Orthod 76:739-744

9. Lapatki BG, Baustert D, Schulte-Monting J, Frucht S, Jonas IE (2006) Lip-to-incisor relationship and postorthodontic long-term stability of cover-bite treatment. Angle Orthod 76:942-949

10. Burstone CJ (1966) The mechanics of the segmented arch techniques. Angle Orthod 36:99-120

11. Liang W, Rong Q, Lin J, Xu B (2009) Torque control of the maxillary incisors in lingual and labial orthodontics: a 3-dimensional finite element analysis. Am J Orthod Dentofacial Orthop 135:316-322

12. Richter AE, Arruda AO, Peters MC, Sohn W (2011) Incidence of caries lesions among patients treated with comprehensive orthodontics. Am J Orthod Dentofacial Orthop 139:657-664

13. Klang E, Beyling F, Knösel M, Wiechmann D (2018) Quality of occlusal outcome following space closure in cases of lower second premolar aplasia using lingual orthodontic molar mesialization without maxillary counterbalancing extraction. Head Face Med 14(1): 17

14. Delivanis HP, Kuftinec MM (1980) Variation in morphology of the maxillary central incisors found in class II, division 2 malocclusions. Am J Orthod 78:438-443

15. Knösel M, Jung K, Gripp-Rudolph L, Attin T, Attin R, Sadat-Khonsari $\mathrm{R}$ et al (2009) Changes in incisor third-order inclination resulting from vertical variation in lingual bracket placement. Angle Orthod 79:747-754

16. Burstone CJ, Pryputniewicz RJ (1980) Holographic determination of centers of rotation produced by orthodontic forces. Am J Orthod 77:396-409

17. Björk A, Skieller V (1977) Growth of the maxilla in three dimensions as revealed radiographically by the implant method. Br J Orthod 4:53-64

18. Smith RJ, Burstone CJ (1984) Mechanics of tooth movement. Am J Orthod 85:294-307

19. Simon M, Keilig L, Schwarze J, Jung BA, Bourauel C (2014) Forces and moments generated by removable thermoplastic aligners: incisor torque, premolar derotation, and molar distalization. Am J Orthod Dentofacial Orthop 145:728-736

20. Rossini G, Parrini S, Castroflorio T, Deregibus A, Debernardi CL (2015) Efficacy of clear aligners in controlling orthodontic tooth movement: a systematic review. Angle Orthod 85:881-889

21. Castroflorio T, Garino F, Lazzaro A, Debernardi C (2013) Upper-incisor root control with Invisalign appliances. J Clin Orthod 47:346-351

22. Hussels W, Nanda RS (1987) Effect of maxillary incisor angulation and inclination on arch length. Am J Orthod Dentofacial Orthop 91:233-239

23. O'Higgins EA, Kirschen RH, Lee RT (1999) The influence of maxillary incisor inclination on arch length. Br J Orthod 26:97-102

24. Sangcharearn Y, Ho C (2007) Maxillary incisor angulation and its effect on molar relationships. Angle Orthod 77:221-225

25. Bantleon HP, Droschl H (1987) Measurement of force and torque rates for the correction of vertically uprighting the anterior teeth. Z Stomatol 84:251-263

26. Rauch ED (1959) Torque and its application to orthodontics. Am J Orthod 45:817-830

27. Canal P, Delsol L, Wiechmann D (2016) Orthodontie linguale. Elsevier Masson, Paris

28. Andrews LF (1972) The six keys to normal occlusion. Am J Orthod 62:296-309
29. Cash AC, Good SA, Curtis RV, McDonald F (2004) An evaluation of slot size in orthodontic brackets-Are standards as expected? Angle Orthod 74:450-453

30. Cattaneo PM, Salih RA, Melsen B (2013) Labio-lingual root control of lower anterior teeth and canines obtained by active and passive self-ligating brackets. Angle Orthod 83:691-697

31. Zimmer B, Sino H (2018) Coordinating bracket torque and incisor inclination. Part 3: validity of bracket torque values in achieving norm inclinations. J Orofac Orthop 79:320-327

32. Dalstra M, Eriksen H, Bergamini C, Melsen B (2015) Actual versus theoretical torsional play in conventional and self-ligating bracket systems. J Orthod 42:103-113

33. Mittal M, Thiruvenkatachari B, Sandler PJ, Benson PE (2015) A three-dimensional comparison of torque achieved with a preadjusted edgewise appliance using a Roth or MBT prescription. Angle Orthod 85:292-297

34. Graber L, Vanarsdall R, Vig K (2011) Orthodontics: current principles and techniques, 5th edn. Elsevier, St Louis

35. Rummel V, Wiechmann D, Sachdeva RC (1999) Precision finishing in lingual orthodontics. J Clin Orthod 33:101-113

36. Wiechmann D (2000) Lingual orthodontics (part 4): economic lingual treatment (ECO-lingual therapy). J Orofac Orthop 61:359-370

37. Vu J, Pancherz H, Schwestka-Polly R, Wiechmann D (2012) Correction of class II, division 2 malocclusions using a completely customized lingual appliance and the Herbst device. J Orofac Orthop 73:225-235

38. Al-Qabandi SM (2013) Slot dimension of completely customized lingual orthodontic brackets-a comparative analysis. Master's thesis in Lingual Orthodontics. Hannover Medical School, Department of Orthodontics

39. Lossdörfer S, Bieber C, Schwestka-Polly R, Wiechmann D (2014) Analysis of the torque capacity of a completely customized lingual appliance of the next generation. Head Face Med 10:4

40. Lossdörfer S, Schwestka-Polly R, Wiechmann D (2013) Control of lower incisor inclination with a completely customized lingual appliance for dentoalveolar compensation of class III malocclusion. J Orofac Orthop 74:381-396

41. Jacobs C, Katzorke M, Wiechmann D, Wehrbein H, SchwestkaPolly R (2017) Single tooth torque correction in the lower frontal area by a completely customized lingual appliance. Head Face Med 13:18

42. Bock NC, Ruf S, Wiechmann D, Jilek T (2016) Dentoskeletal effects during Herbst-Multibracket appliance treatment: a comparison of lingual and labial approaches. Eur J Orthod 38:470-477

43. Demling A, Dittmer MP, Schwestka-Polly R (2009) Comparative analysis of slot dimension in lingual bracket systems. Head Face Med 5:27

44. Pauls A (2015) Therapeutic accuracy of the completely customized lingual appliance WIN. Master's thesis in Lingual Orthodontics. Hannover Medical School, Department of Orthodontics

45. Wiechmann D, Schwestka-Polly R, Pancherz H, Hohoff A (2010) Control of mandibular incisors with the combined Herbst and completely customized lingual appliance-a pilot study. Head Face Med 6:3

46. Proffit WR, Fields HW, Larson B, Sarver DM (2018) Contemporary orthodontics, 6th edn. Elsevier, Philadelphia

47. Cattaneo PM, Dalstra M, Melsen B (2008) Moment-to-force ratio, center of rotation, and force level: a finite element study predicting their interdependency for simulated orthodontic loading regimens. Am J Orthod Dentofacial Orthop 133:681-689

48. Nahoum HI (2008) Moment-to-force ratio. Am J Orthod Dentofacial Orthop 134:176-177 
Hier steht eine Anzeige.

Springer 